\title{
Early growth of rubber in the Dry Zone of Sri Lanka: an investigation in Vavuniya District
}

\author{
S M M Iqbal*, V H L Rodrigo*, E S Munasinghe*, B M D C Balasooriya*, \\ K V V S Kudaligama*, P M M Jayathilake* and R P S Randunu* \\ * Rubber Research Institute of Sri Lanka, Dartonfield, Agalawatta, Sri Lanka
}

\begin{abstract}
In view of supporting the rubber product manufacturing sector in Sri Lanka and providing stable income for the peasant community, rubber cultivation is in the process of expanding to the drier regions of the country. Under this programme, rubber was introduced to the Northern region (Dry Zone) in 2010 with a tentative set of agronomic protocols. The present study showed that rubber cultivated in this region under smallholder conditions together with irrigated short term crops, has shown reasonable growth with an average annual girth expansion rate of $8.6 \mathrm{~cm}$. A growth curve for the immature phase of rubber was established for the first time for the dry zone of Sri Lanka. Despite some adverse effects of dry weather on photosynthesis and associated physiological parameters, no evidence of permanent damages to photosynthetic apparatus was recorded. Further actions to be taken in the expansion process of rubber cultivation in this region are also discussed.
\end{abstract}

Key words: dry climate, growth curve, Hevea, photosynthesis

\section{Introduction \\ Urbanization and industrialization prevent the expansion of rubber cultivation further in its traditional rubber growing wet regions (WZ). Consequently, the Government of Sri Lanka (GoSL) has decided to expand rubber cultivation to drier non- traditional regions of the country. For this purpose, East and North regions of the country have been focused not only because their land availability per capita is reasonably higher but also because of livelihood consideration of the people,}

who were entangled in 30 year war. In this endeavor, rubber was initially grown in the Intermediate Zone (IZ) of Eastern province and it was found to be successful in terms of both agronomic (Iqbal et al., 2010) and social aspects (Rodrigo et al., 2009). With that back ground, GoSL suggested to expand the rubber cultivation to the Dry zone (DZ) of East and North regions. However DZ being drier than IZ, agro-management practices in DZ would be more problematical than those in either $\mathrm{WZ}$ or IZ. As experienced in India, such 
S M M Iqbal et al.

condition may prolong the immature period and result in decline in yields (Datta et al., 2010; Vijayakumar et al., 1998). Water availability for irrigation is very limited in this region and the lands where water available are devoted for more remunerative short-term cash crops (Rodrigo et al., 2009). It is expected to grow rubber under rain fed conditions; however, some farmers are interested in growing rubber with some level of irrigation. Therefore, a set of tentative recommendations was issued to cultivate rubber in DZ targeting initially the Vavuniya District (Rodrigo et al., 2011a). Accordingly, rubber cultivation began in this region in 2010 with few farmers engaged in cultivating annual and semi-perennial crops. By end of 2015, about 31 ha of rubber have been cultivated with 20 farmers in Vavuniya district (under the area of Vavuniya South Divisional Secretariat). Further expansion of rubber in this region or any other area coming under $\mathrm{DZ}$ is to be decided upon the success of the already planted rubber. Although rubber trees planted in Vavuniya have not been harvested yet, the growth pattern and associated physiological performance of rubber should provide sufficient information on the success of rubber cultivation in this region. Therefore, the present study was aimed to quantify the growth of immature rubber in this region and to investigate the impact of the prevailing climatic conditions on its physiological parameters.

\section{Materials and Methods Site details;}

The study began in 2010 with the initial establishment of rubber in the Northern region. Details of rubber fields established in Vavuniya District (Vavuniya South and North) from 2010 onwards are shown in Table 1. All of these rubber holdings were established jointly by the Rubber Research Institute of Sri Lanka (RRISL) and Rubber Development Department (RDD) as a smallholder development programme. It was observed that successful sites were confined to the Divisional Secretariat region of Vavuniya South. To all sites, rubber, genotype RRIC 121, was introduced as an intercropping system in which annuals (e.g. Capsicum and Tomatoes) and semi-perennials (e.g. Papaya and Banana) were grown along with rubber (Fig. 1). Being a crop with no quick return, rubber was the subsidiary crop in the management of these intercropping systems in these regions. Since seasonal and semiperennials were irrigated with drip or low height sprinkler systems, rubber plants also received reasonable amount of water for a period about 2-3 years after which cultivation of annuals and semi-perennials were discontinued due to the shade of the rubber canopy. Nevertheless, water received by rubber plants during dry spells was just sufficient for survival. Thick $(15 \mathrm{~cm})$ mulch was applied around the rubber plants mostly with crop debris to conserve the soil water. Fertilizer to rubber plants was applied with 
$\mathrm{N}: \mathrm{P}: \mathrm{K}: \mathrm{Mg}$ ratio of R/SA 7:9:9:4 thrice a year with doses of $450 \mathrm{~g}, 900 \mathrm{~g}, 1350 \mathrm{~g}$, and $1800 \mathrm{~g}$ per plant per year from $1^{\text {st }}$ to $5^{\text {th }}$ year of growth, respectively (Advisory Circular 2012). Other agromanagement practices were conducted as per the tentative recommendations issue to cultivate rubber in DZ targeting initially the Vavuniya District (Rodrigo et al., 2011a). The rainfall data in Vavuniya for the study period were collected from the Meteorological Department of GoSL.
Table 1. Details of rubber fields successfully established in the Northern Province (Vavuniya district) of Sri Lanka

\begin{tabular}{rrr}
\hline Year & $\begin{array}{r}\text { Extent } \\
\text { (ha) }\end{array}$ & No. of holdings \\
\hline 2010 & 2.6 & 07 \\
2011 & 17.8 & 15 \\
2012 & 2.1 & 15 \\
2013 & 31.6 & 113 \\
2014 & 6.1 & 01 \\
\hline
\end{tabular}

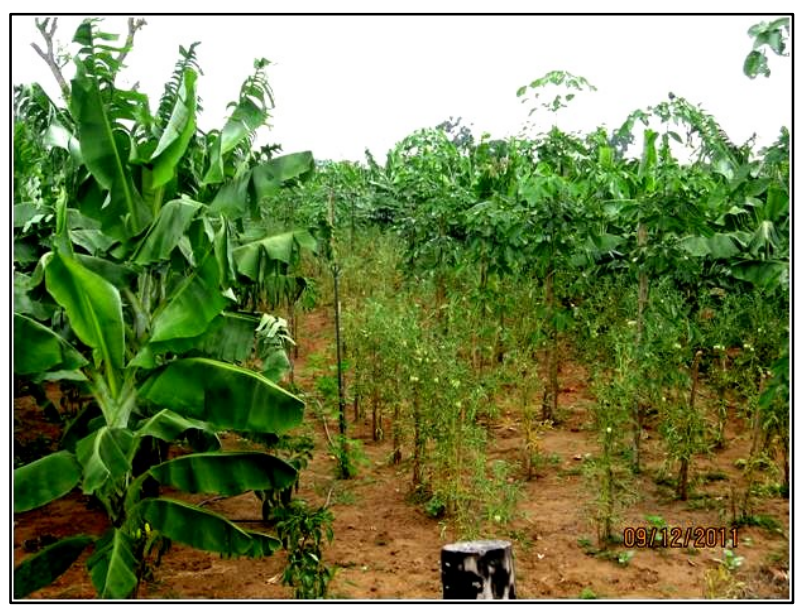

Fig. 1. Rubber (Clone RRIC 121) planted with annuals (Capsicum and Tomatoes) and semiperennial (Banana) in Vavuniya South

Growth and physiological

measurements;

Growth of rubber in terms of tree circumference (girth) at $120 \mathrm{~cm}$ height was measured continuously at approximately one year intervals in two sites planted in December 2010. In addition, five sites selected from subsequently planted years (three from 2011 and one from 2012 and 2013 plantings) were also used for the same growth measurement. In each site, 100 trees were selected at the centre of the plot for girth measurements.

Physiological assessments comprised building up the light response curve for 
S M M Iqbal et al.

photosynthesis (LRC) with associated parameters, i.e. apparent quantum yield $\left(\phi_{\text {app }}\right)$ and light saturated rate of photosynthesis $\left(\mathrm{A}_{\max }\right.$ ), measurements on stomata conductance and chlorophyll $a$ fluorescence. A portable infra-red gas analyser (IRGA) with open system (LI6400, Li-Cor Inc., Lincoln, NE, USA.) was used for building up LRC whilst porometer (Delta T AP4, UK) was used for the measurements of stomatal conductance under field conditions. Assessments were done in 2014 in two sites planted in 2010 and 2011 (i.e. at the stages of three and four years after planting) with two sets of measurements representing wet and dry seasons (N.B. irrigation has been stopped at these stages). In each season, LRCs were established with photosynthetic measurements taken at 11 light levels (given with built in 6400-02B Red/Blue light source in IRGA) in the morning $(0800-1000 \mathrm{~h})$ and afternoon (1400$1600 \mathrm{~h}$ ) hours of the day. In the case of stomatal conductance, diurnal measurements were conducted at three time points representing morning $(0800$ $1000 \mathrm{~h}$ ), midday (1100-1300h) and afternoon (1400-1600 h) hours of the day. Both measurements were confined to the leaves in the recently matured leaf whorl (i.e. leaves considered to be most active). At each time point, LRC was built up with single set of measurements with a single leaf whilst measurements on stomatal conductance were confined to twelve leaves at a time from four plants in the most recently matured leaf whorl.
Leaf chlorophyll $a$ fluorescence emission was measured in terms of the ratio of variable $\left(\mathrm{F}_{\mathrm{v}}\right)$ to maximal $\left(\mathrm{F}_{\mathrm{m}}\right)$ fluorescence with the fluorometer OptiSc (OSP 5, UK). Measurements were taken at three time points representing morning (0800-1000 h), midday (1100-1300h) and afternoon (1400-1600 h). At a given time point, nine leaves from three plants selected from the most recently matured leaf whorls (i.e. leaves considered to be most active) were used for the measurements after 20 minutes of dark adaptation. Although the assessments on photosynthesis and stomatal conductance represented both wet and dry periods, fluorescence measurements were confined to the dry period in 2016 due to the unavailability of the instrument.

Data analyses;

Plants growth is not generally linear; hence, a logistic function representing the typical ' $S$ ' type curve (Equation 1) was fitted to time bound repeatedly measured girth values of rubber using Genstat Statistical Package (GenStat Release 11.1UK).

Equation 1:

Girth $=a+\frac{c}{1+\exp (-b(x-m)}$

Logistic function fitted to the girth expansion of rubber plants where $a, b, c$ and $\mathrm{m}$ are constants and $\mathrm{x}$ stands for months after planting. Of the growth 
function, parameters' a' plus 'c' represent the upper asymptote whilst ' $b$ ' is a slope parameter. The time point of inflexion of the growth curve is given by ' $m$ '.

Light-response curve for $\mathrm{CO}_{2}$ assimilation were derived by fitting the data to a non-rectangular hyperbola (Equation 2) (Prioul and Chartier, 1977) using a computer software package (Photosyn Assistant, Ver. 1.1.2.) and the parameters, light saturated rate of photosynthesis $\left(\mathrm{A}_{\max }\right)$ and the apparent quantum yield of rubber $\left(\phi_{\text {app }}\right)$ were derived.

Equation 2:

$$
A=\frac{\emptyset a p p Q+A m a x-\sqrt{(\varnothing a p p Q+A m a x)^{2}-4 \emptyset a p p Q k A m a x}}{2 k}
$$

Where, Q is the incident photon flux density, $\phi_{\text {app}}, \mathrm{k}$ and $\mathrm{A}_{\max }$ are the initial slope (apparent quantum yield), convexity and upper asymptote of the light-response curve (light saturated rate of photosynthesis). The value for convexity was kept as a constant (0.65). Presentation of data is rather descriptive showing the mean values for respective periods along with Standard Error.

\section{Results}

Total amount of rainfall received per year within the study period was in the range of 1319 to $2106 \mathrm{~mm}$ (Fig. 2). Depicting the dry climatic conditions of the region, only 2-3 months per year received rainfall over $200 \mathrm{~mm}$ and 1-2 months with over $300 \mathrm{~mm}$. In most of years, over 3 months dry periods (less than $50 \mathrm{~mm}$ per month) were recorded and there was an instance of having nine months dry period (i.e. in 2014) with only one month receiving over $50 \mathrm{~mm}$ but less than $100 \mathrm{~mm}$ rainfall. In general, annual rainfall distribution is rather unimodal and dry conditions prevailed in the months of May, June, July, August and September.

Irrespective of the site differences, the logistic function fitted for plants girth has been able to demonstrate the typical 'S' curve of plant growth with two dominant phases, i.e. initial increasing rate and then declining rate of plant growth (Fig. 3). The point of inflexion given by the parameter ' $\mathrm{m}$ ' shows that phase change occurred at 38 MAP. If plant growth is assumed to be linear over time then girth expansion shows $8.6 \mathrm{~cm}$ increase per year.

LRCs built up for wet and dry periods and then morning and afternoon hours of the day showed significant differences (Fig. 4). In particular, light saturated rate of photosynthesis $\left(\mathrm{A}_{\max }\right)$ varied largely with greater values during wet than in dry periods. Also, $\mathrm{A}_{\max }$ was higher in morning hours than in afternoon in both wet and dry periods. Further, the effect of dry weather on $A_{\max }$ was more severe than that of wet period. However, with the afternoon value in the dry period being higher 
than the morning value in the dry period. Nevertheless, $A_{\max }$ was higher in the four year (planted in 2010) than in three year (planted in 2011) old plants (Table 2). Mean apparent quantum yield $\left(\phi_{\text {app }}\right)$ was least affected with values around 0.04 , irrespective of the season and the time of the day. However, it also showed higher values in the four than in the three year old plants.

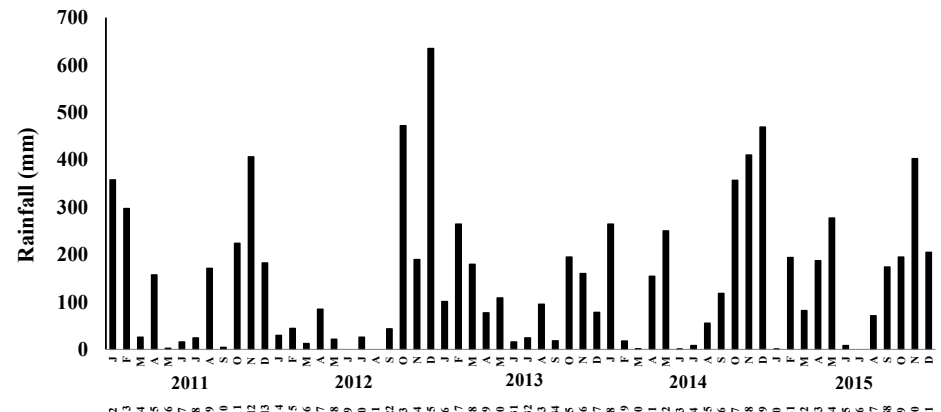

Months After Planting

Fig. 2. Monthly distribution of rainfall in the Dry zone of Northern Province, Vavuniya South from January 2011 to December 2015

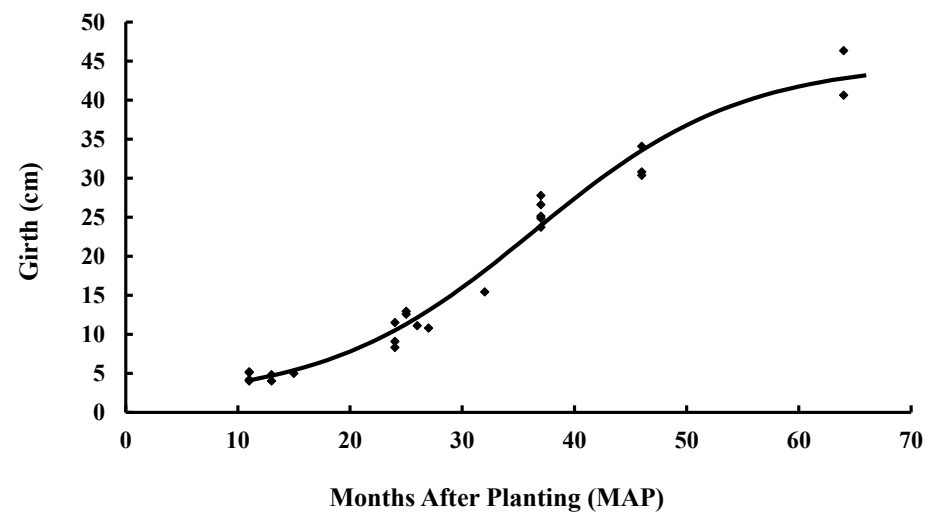

Fig. 3. Girth expansion of rubber trees in the Dry zone of Northern Province, Vavuniya South. The best fitted line obtained using the logistic function (Equation 1); Girth $=1.47+43.71 /[1+\exp (-0.108 *(\mathrm{MAP}-36.36))] \mathrm{R}^{2}-97 \%$ 


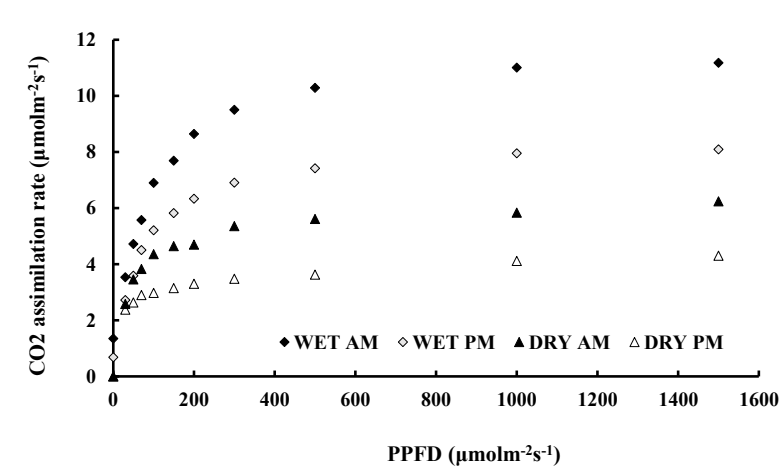

Fig. 4. Diurnal variation in photosynthetic $\mathrm{CO}_{2}$ assimilation of rubber with respect to different light levels under wet and dry conditions (pooled values of rubber planted at the ages of three and four). Light was measured as the photosynthetically-active photon flux density (PPFD)

Table 2. The mean apparent quantum yield $\left(\phi_{\text {app }}\right)$ and maximum light saturated rate of photosynthetic $\mathrm{CO}_{2}$ assimilation $\left(A_{\max }\right.$ ) determined from the light response curves shown in Figure 3.

\begin{tabular}{lcccc}
\hline \multirow{2}{*}{$\begin{array}{l}\text { Year of } \\
\text { planting (Age) }\end{array}$} & \multicolumn{2}{c}{$\begin{array}{c}\text { Mean apparent quantum yield } \\
\left(\phi_{\text {app }}\right)\end{array}$} & \multicolumn{2}{c}{$\begin{array}{c}\text { Mean } \mathbf{A}_{\max } \\
\left(\mu \mathrm{mol} \mathrm{CO}_{2} \mathrm{~m}^{-2} \mathrm{~s}^{-1}\right)\end{array}$} \\
\cline { 2 - 5 } & \multicolumn{2}{c}{ Wet period } & \multicolumn{2}{c}{ Wet period } \\
\cline { 2 - 5 } & AM & PM & AM & PM \\
\hline 2010 (4 years) & $0.058( \pm 0.016)$ & $0.064( \pm 0.003)$ & $12.27( \pm 0.197)$ & $8.55( \pm 0.312)$ \\
2011 (3 years) & $0.037( \pm 0.012)$ & $0.045( \pm 0.015)$ & $10.00( \pm 0.410)$ & $5.36( \pm 0.445)$ \\
\hline & \multicolumn{2}{c}{ Dry period } & \multicolumn{2}{c}{ Dry period } \\
\cline { 2 - 5 } & AM & PM & AM & PM \\
\hline 2010 (4 years) & $0.047( \pm 0.006)$ & $0.055( \pm 0.028)$ & $7.27( \pm 0.264)$ & $3.87( \pm 0.329)$ \\
2011 (3 years) & $0.036( \pm 0.015)$ & $0.053( \pm 0.019)$ & $5.04( \pm 0.209)$ & $3.41( \pm 0.498)$ \\
\hline
\end{tabular}

According to the diurnal variation in chlorophyll a fluorescence emission, $\mathrm{F}_{\mathrm{v}} / \mathrm{F}_{\mathrm{m}}$ ratio was greater in the morning than in afternoon, and also despite the high level of variation, the midday day values showed the lowest $F_{v} / F_{m}$ (Fig. 5). However in general, all values recorded for $\mathrm{F}_{\mathrm{v}} / \mathrm{F}_{\mathrm{m}}$ were above 0.6 .

Diurnal variation in stomatal conductance $\left(\mathrm{g}_{0}\right)$ was more prominent in the wet than in the dry period, with the lowest values in the midday and then in the afternoon (Fig. 6). Stomatal conductance recorded in the morning of the wet period was the highest with the values exceeding $1 \mathrm{cms}^{-1}$. Although some level of diurnal variation of $g_{0}$ was shown during dry period, the values recorded for $\mathrm{g}_{0}$ in the morning were less than the values for midday in the wet period. Also, diurnal variation of $g_{0}$ in the dry period was in the range of 0.2 $\mathrm{cms}^{-1}$. 


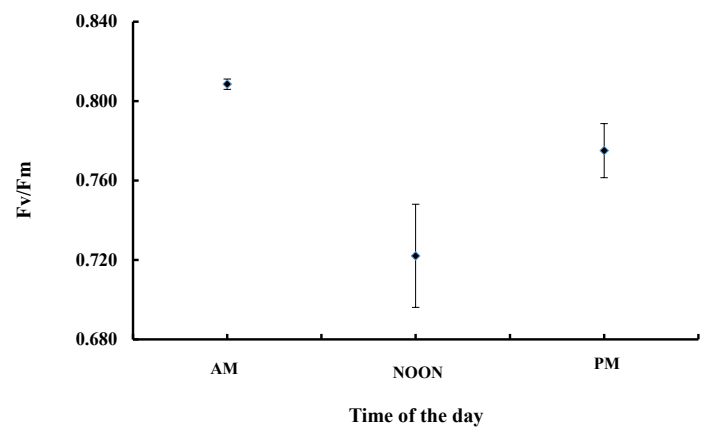

Fig. 5. Leaf chlorophyll $a$ fluorescence emission $F v / F m$ ratio of rubber in dry period (pooled values of year 2010 and 2011). Error bars represent \pm standard errors for nine values

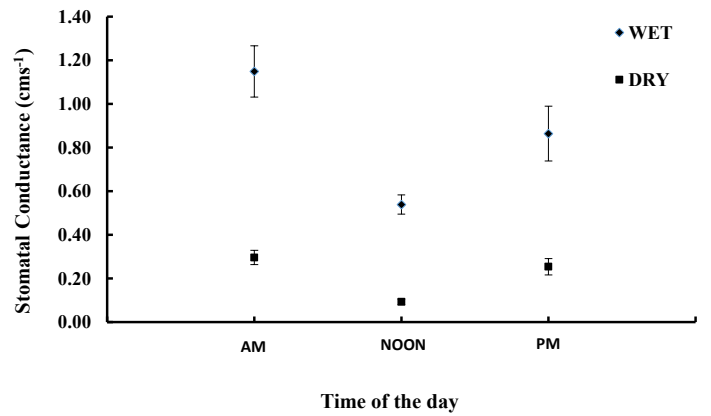

Fig. 6. Stomatal conductance $\left(\mathrm{g}_{0}\right)$ of rubber planted in 2010 (at the age of four years). Each $\mathrm{g}_{0}$ value represents the mean of 12 measurements recorded during the morning (0900$1100)$, midday (1200-1400) and evening (1500-1700) in wet and dry periods in year 2014. Error bars indicate standard error of means

\section{Discussion}

Rubber cultivation in suboptimal conditions is important to meet the incountry demand for raw rubber from the rubber product manufacturing sector. The present level of value addition to raw rubber produced within the country has already exceeded $70 \%$ and at present, raw rubber imports in Sri Lanka are more than exports (MPI, 2015).
Hence, in order to provide uninterrupted supply of raw rubber, rubber cultivation has to be expanded from traditional to other potential areas. With low level of opportunity cost for labour, rubber cultivation in North and East regions would create a win-win situation providing additional rubber to the manufacturing sector of the country and 
also a stable income to the resource poor farmers in the region.

Growth of rubber as shown by the girth expansion has been satisfactory with an average of $8.6 \mathrm{~cm}$ per year which is comparable with general circumstance in the traditional Wet Zone. This is mainly due to the irrigation provided at early stages of growth. If this could be continued, rubber trees in this region would come to the tappable stage (i.e. $50 \mathrm{~cm}$ girth) within seven years. Although this would be slightly higher than the expected number years in immaturity (i.e. 5-6 years), the growth rate achieved under suboptimal conditions in Sri Lanka is rather remarkable as nine years of immaturity has been recorded for rubber in suboptimal regions in India, i.e. Konkan region of Western India (Chandrashekar et al., 1998) and Bastar region in Chattisgarh state located in central India (Krishan et al., 2007; Krishan 2013; 2015). However, the situation might have differed with no irrigation provided in early stages. As indicated by the parameter ' $\mathrm{m}$ ' in the logistic function fitted to girth values, the transition in growth rate from increasing to decreasing took place at about 38 MAP. Evidence in traditional WZ shows that this occurs at about 42-48 MAP (Rodrigo et al., 2005). Intercrops grown with rubber faded off after $3^{\text {rd }}$ year of growth due to the canopy cover given by rubber and then, irrigation to rubber fields was also terminated. This would be the reason for such earlier transition in growth rates. If water supply were continued, increased growth rates would have continued with trees coming to harvestable stage by $5-6$ years as experienced in the WZ. Perhaps, plant growth and then yield of rubber would be higher in DZ under irrigated conditions since plants would receive greater level of total sunlight than in $\mathrm{WZ}$ for a given period time.

Seasonal variation in rainfall would have caused seasonal fluctuation in girth expansion as evidenced elsewhere (Chandrashekar et al., 1998) However, no such changes could be detected since the frequency of girth measurements (i.e. once a year) is not intensive enough for such analysis. However, such study should be useful in quantifying the drought effects on tree growth and yield, hence proposed for future research.

Effect of drought on plant growth is illustrated by the decrease in the light saturated rate of photosynthesis $\left(\mathrm{A}_{\max }\right)$. The sensitivity of $A_{\max }$ even to shortterm water stress is shown by the decrease in $\mathrm{A}_{\max }$ in the afternoon from the values recorded in the morning. As evidenced by the values recorded for apparent quantum yield $\left(\phi_{\text {app }}\right)$ in photosynthesis and the ratio of variable to maximum fluorescence $\mathrm{F}_{\mathrm{v}} / \mathrm{F}_{\mathrm{m}}$, (i.e. values above 0.035 and 0.6 , respectively), no permanent damage to photosynthetic mechanism or photoinhibition has occurred due to the dry weather. However, reduced water status in the plants would have resulted in stomatal closure (Chandrashekar et al., 1990) as shown by low levels of 
S M M Iqbal et al.

stomatal conductance during dry period and then, down regulation in photosynthesis would have reduced $\mathrm{A}_{\max }$ and overall in photosynthesis rate. Though not up to the same levels in dry periods, the same phenomenon would occur even in the afternoon hours of the wet periods with time bound reduction in water status of plants (i.e. due to heavy radiation loads received during midday period). Such diurnal effects on photosynthesis and other physiological parameters have been recorded in several previous studies on rubber (Senevirathna et al., 2003 and Iqbal and Rodrigo, 2006) and other crops (Mohotti and Lawlor, 2002; Ramalho et al., 1997 and Dang et al., 1991).

The response of plants to dry weather would vary with the genotype. For instance in India, Chandrashekar et al. (1990) has recorded such genotype variation in stomatal conductance under drought conditions. Therefore, testing of rubber clones in $\mathrm{DZ}$ is to be given as a priority basis (N.B. this is in progress at present) with that clones performing better than the presently used genotype could be identified for this region.

Acceptable level of growth rates recorded for rubber in DZ confirms the suitability of the agronomic protocol developed (i.e. the tentative recommendation issued) for rubber cultivation in this region (Rodrigo et al., 2011a). Therefore, it could continuously be adopted in the expansion process of rubber in DZ. However, the interest shown for rubber cultivation by the Tamil community in North is not encouraging. Although a few social studies on rubber cultivation have been conducted in this region (Rodrigo et al., 2011b), the real cause is still unknown. Therefore, systematic social studies are required to identify causal factors for the same before investing on rubber in Tamil dominated areas in the Northern Province.

In conclusion, the present study showed that the growth of rubber in Northern region (DZ) of Sri Lanka under smallholder conditions (having irrigated intercrops in first three years) has been able to achieve reasonable growth with an average annual girth expansion rate of $8.6 \mathrm{~cm}$. Despite some effects of dry weather on photosynthesis and associated physiological parameters, no evidence for permanent damages to photosynthetic apparatus was recorded.

\section{Acknowledgements}

The authors express gratitude to the National Science Foundation for providing the funds for this study under the contract Research Grant No RG/2011/AG/10. Also, assistance given by the staff of RRISL and the facilities provided by RRISL are acknowledged.

\section{References}

Advisory Circular (2012). Fertilizer for rubber. Dry \& Intermediate zone (Provisional Recommendation) Soils and Plant Nutrition Department, Rubber Research Institute of Sri Lanka. Circular No: SPN/2012-1.

Chandrashekar, T R, Nazeer, M A, Marattukalam, J G, Prakash, G P, Annamalainathan, $\mathrm{K}$ and Thomas, $\mathrm{J}$ 
(1998). An analysis of growth and drought tolerance in rubber during the immature phase in a dry sub-humid climate. Experimental Agriculture 34, 287-300.

Chandrasekhar, T R, Jana, M K, Thomas, J, Vijayakumar, K R and Sethuraj, M R (1990). Seasonal changes in physiological characteristics and yield in newly opened trees of Hevea brasiliensis in North Konkan. Indian Journal Nat Rub Res 3, 88-97.

Dang, Q L, Lieffers, V J, Rothwell, R L and Macdonald, S E (1991). Diurnal variation and interrelations of ecophysiological parameters in three peat land woody species under different weather and soil moisture conditions. Oecologia 88 (3), 317324.

Datta, B, Thapaliyal, A P, Ravichandran, S, Singh, M and Nair, N U (2010). Good agricultural practices for non-traditional natural rubber growing areas experiencing extreme agro climatic conditions. Proceeding of the IRRDB Workshop on Climate and Rubber Cultivation. July 28-30, 2010 Rubber Research Institute of India, Kottayam, India.

Iqbal, S M M, Rodrigo, $\mathrm{V} \mathrm{H}$ L and Karunathilake, P K W (2010). Feasibility of rubber (Hevea brasiliensis Muell. Arg.) cultivation in Eastern province of Sri Lanka with the peasant community. Journal Rubber Research Institute of Sri Lanka 90, 18-30.

Iqbal, S M M and Rodrigo, V H L (2006). Feasibility of rubber (Hevea brasiliensis muell. arg.) cultivation in the eastern province of Sri Lanka; A non traditional area for rubber. Preprints of papers, International Natural Rubber
Conference, 13-14 November 2006, Ho Chi Minh City, Vietnam. P.571-584.

Krishan, B (2015). Growth assessment of popular clones of natural rubber (Hevea brasiliensis) under warm dry climatic conditions of Chattisgarh state, Central India. Journal of Experimental Biology and Agricultural Sciences 3 (2), 157161.

Krishan, B (2013). Performance of some Hevea clones under the dry sub- humid climate in Odisha. Rubber Science 26, 127-132.

Krishan, B, Rao, K N and Nazeer, M A (2007). Growth performance of Hevea brasiliensisin a dry sub-humid climate of Bastar region in central Eastern India. Natural Rubber Research 20, 56-60.

MPI (2016). Plantation Sector Pocket Book. Ministry of Plantation Industries, Sri Lanka.

Mohotti, A J and Lawlor, D W (2002). Diurnal variation of photosynthesis and photoinhibition of tea: effects of irradiance and nitrogen supply during growth in the field. Journal of Experimental Botany 53 (113), 313-322.

Prioul, J L and Chartier, P (1977). Partitioning of transfer and carboxylation components of intracellular resistance to photosynthetic $\mathrm{CO}_{2}$ fixation: A critical analysis of the methods used. Annals of Botany 41, 789800.

Ramalho, J C, Pons, T L, Gronveld, H W and Nunes, M A (1997). Photosynthetic responses of Coffea arabica leaves to a short-term high light exposure in relation to $\mathrm{N}$ availability. Physiologia Plantarum 101, 229-239.

Rodrigo, V H L, Iqbal, S M M and Munasinghe, E S (2009). Rural livelihood and rubber and rubber cultivation in Eastern Province of Sri 
S M M Iqbal et al.

Lanka. Journal Rubber Research Institute of Sri Lanka 89, 58-69.

Rodrigo, V H L, Iqbal, S M M and Seneviratne, W M G (2011a). Rubber Cultivation in the Northern Region of Sri Lanka: Present status and Interim Recommendations. The report presented to the Minister of Plantation Industires, November 2011, Rubber Research Institute of Sri Lanka. 13.

Rodrigo, V H L, Iqbal, S M M and Dharmakeerthi, R S (2011b). Potential for rubber (Hevea brasiliensis Muell. Arg.) cultivation in the Eastern Province of Sri Lanka. Journal of National Science Foundation, Sri Lanka 39 (4), 403-411.

Rodrigo, V H L, Stirling, C M, Silva, T U K and Pathirana, P D (2005). The growth and yield of rubber at maturity is improved by intercropping with banana during the early stage of rubber cultivation. Field Crops Research 91, 23-33.
Senevirathna, A M W K, Stirling, C M and Rodrigo, V H L (2003). Growth, photosynthetic performance and shade adaptation of rubber (Hevea brasiliensis) grown in natural shade. Tree Physiology 23,705-712.

Vijayakumar, K R, Dey, K R, Chandrasekhar, T R, Devakumar, A S, Mohankrishna, T, Panjeeva Rao and Sethuraj, M R (1998). Irrigation requirement of rubber trees (Hevea brasiliensis) in the sub humid tropics. Agricultural Water Management 35(3), 245-259.

Address for correspondence: Dr S M M Iqbal, Principal Research Officer, Adaptive Research Unit, Rubber Research Institute of Sri Lanka, Dartonfield, Agalawatta, Sri Lanka.

e-mail:smmiq57@gmail.com 